\title{
Flow Boiling Heat Transfer of Refrigerant R-134a in Copper Microchannel Heat Sink
}

\author{
Vladimir V. KUZNETSOV*, Alisher S. SHAMIRZAEV \\ * Corresponding author: Tel.: ++7(383) 3307121; Fax: ++7(383) 3308480; Email: vladkuz@itp.nsc.ru \\ Kutateladze Institute of Thermophysics SB RAS, Novosibirsk, Russia
}

\begin{abstract}
In this paper we present experimental data on heat transfer and pressure drop characteristics at flow boiling of refrigerant R-134a in a horizontal microchannel heat sink. The primary objective of this study is to establish experimentally how the local heat transfer coefficient and pressure drop correlate with the heat flux, mass flux and vapor quality. The copper plate of microchannel heat sink contains 21 microchannels with $335 \times 930 \mu \mathrm{m}^{2}$ cross-section. The microchannel plate and heating block were divided by the partition wall for the local heat flux measurements. Distribution of local heat transfer coefficients along the length and width of the microchannel plate were measured in the range of external heat fluxes from 50 to $500 \mathrm{~kW} / \mathrm{m}^{2}$; the mass flux was varied within $200-600 \mathrm{~kg} / \mathrm{m}^{2} \mathrm{~s}$, and pressure was varied within $6-16$ bar. The obvious impact of heat flux on the magnitude of heat transfer coefficient was observed. It shows that nucleate boiling is the dominant mechanism for heat transfer. The new model of flow boiling heat transfer, which accounts nucleate boiling suppression and liquid film evaporation, was proposed and verified experimentally in this paper.
\end{abstract}

Keywords: Microchannel Heat Sink, Heat Transfer, Flow B oiling, Boiling Suppression, Film Evaporation

\section{Introduction}

Heat transfer under the conditions of phase change in microchannels represents a fastdeveloping field of science. It received increasing attention due to the trend towards miniaturization in a variety of engineering applications, such as thermal management of electronics, micro-evaporators and so on. Development of two-phase microchannel technology requires understanding of thermal aspects of the phase change in microchannel heat sinks under substantial contribution of capillary forces. When one reduces the channel size, wide variety of phenomena that are not typical for conventional tubes becomes apparent. The degree of their manifestation depends not only on the geometric scale, but also on the shape of channels, heat fluxes, pressure, etc. Despite the fact, that this problem was addressed in several studies (e.g. Lee and Mudawar (2005); Bertsch et al. (2009)), flow boiling in microchannel heat sink is still understood incompletely.

The mechanisms of flow boiling heat transfer in minichannels and microchannels were discussed in many papers, for example Thome (2006), Bertsch et al. (2009), Kandlikar (2010), Karayiannis et al. (2012). While there has been general agreement that the heat transfer coefficient increases with increasing heat flux, the effect of vapor quality and mass flux showed opposing trends in some studies. The growth of heat transfer coefficients at high vapor quality was observed by Kuznetsov and Shamirzaev (2007) for refrigerant R-21.

The published models for flow boiling heat transfer prediction are based either on modification of the models obtained for conventional tube (e.g. Kandlikar and Balasubramanian, 2004) or are the specialpurpose models for calculation of heat transfer (Bertsch et al., 2009). The three-zone heat transfer model for elongated bubble flow, for which transient evaporation of a thin film, surrounding the elongated bubble, is essential, was proposed by Thome et al. (2004). Nevertheless, as it was noted by Bertsch et al. (2009), application of existing models to different modes of heat transfer cannot be considered successful.

The pressure drop in microchannel heat sink is 
an important parameter for the design of cooling systems. Complexity of calculating the pressure drop associated with a wide range of vapor quality variation in microchannel heat sink and geometry of microchannel plate. In experiments of Revellin and Thome (2007) adiabatic two-phase pressure drop was measured in micro-tubes with the inner diameters of $509 \mu \mathrm{m}$ and $790 \mu \mathrm{m}$, while using $\mathrm{R}-134 \mathrm{a}$ and R-245fa as the working fluids. Their data in the turbulent regime were predicted by Müller-Steinhagen and Heck (1986) correlation, while no other tested correlation predicted their data satisfactorily.

In this paper we study heat transfer and pressure loss at flow boiling of refrigerant R134a in a horizontal microchannel heat sink, which contains 21 rectangular channels with cross-section dimensions of $930 \times 335-\mu \mathrm{m}^{2}$. The microchannel plate and heating block were mounted in the stainless steel container with two sections divided by the partition wall for the local heat flux measurements. The primary objective of this study is to establish experimentally how the local heat transfer coefficient correlates with the heat flux, mass flux and vapor quality. Using experimental data, the new model of flow boiling heat transfer, which accounts nucleate boiling suppression and liquid film evaporation, was proposed and verified experimentally.

\section{Experimental equipment and methods}

Figure 1 shows the setup for investigation of refrigerant flow boiling heat transfer in microchannel heat sink. Liquid refrigerant R134a was fed from the condenser through the filter and flow controller Bronkhorst HI-TECH to the pre-evaporator via the pump. The refrigerant goes through the pre-evaporator to achieve the flow with desired vapor quality, passes to the microchannel heat think and then goes to the condenser.

Twenty one microchannels were made by precise milling of $335 \mu \mathrm{m}$ wide and $930 \mu \mathrm{m}$ deep micro-slots into the $20 \times 40 \mathrm{~mm}^{2}$ top surface of an oxygen-free copper plate of microchannel heat sink. The distance between

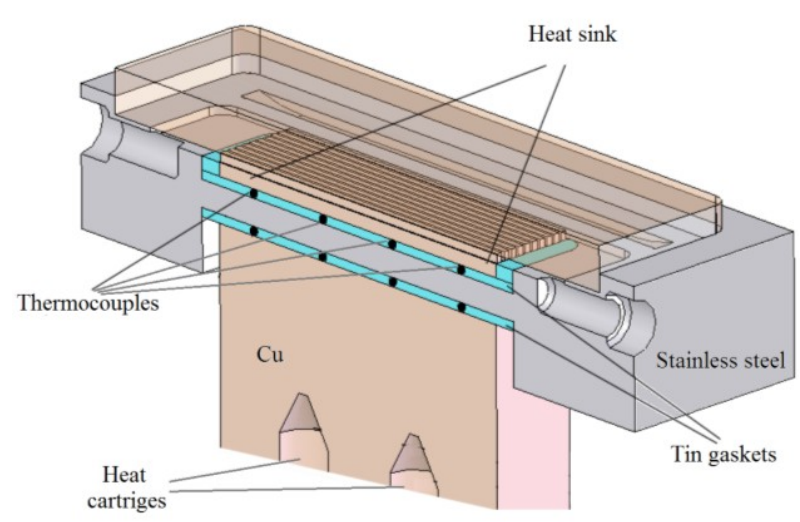

Fig. 1. Schematic of experimental setup.

channels equals to $650 \mu \mathrm{m}$ (fin thickness) at total plate thickness of $2.5 \mathrm{~mm}$. Wall roughness $R a$ was estimated as $1 \mu \mathrm{m}$ from surface roughness measured using an optic microscope.

The microchannel plate and heating block were mounted in the stainless steel container with two sections divided by the partition wall for the local heat flux measurements, see Fig. 1. The thickness of the partition wall equaled $2.51 \mathrm{~mm}$. Tin gaskets with thickness of 0.5 $\mathrm{mm}$ and thermocouples inside were placed between the microchannel plate and partition wall as far as between the heating block and partition wall. Gaskets were melted during the assembly process to reduce the contact thermal resistance. After microchannel plate mounting it was closed by the copper cover and soldered.

The heat was supplied to the test section via the copper block with mounted heat cartridges, which can supply the heat flux of up to 500 $\mathrm{kW} / \mathrm{m}^{2}$. During test the temperatures of tin gaskets were measured in four cross-sections along the heat sink at the distances of $5 \mathrm{~mm}$, $15 \mathrm{~mm}, 25 \mathrm{~mm}$, and $35 \mathrm{~mm}$ from the microchannels inlet, see Fig. 1. In each crosssection two thermocouples were placed along the width of the microchannel plate. The numerical calculations were done to obtain the actual temperatures of internal channels wall and temperature difference through the partition wall. Due to small fin height and high cooper thermal conductivity the temperature of the internal channel wall was almost uniform in the cross-section. 
During the experiments, the temperatures were measured continuously and the standard deviation of each temperature was determined. It was deemed that the regime was stable, if the drift of the wall average temperature did not exceed $0.1 \mathrm{~K}$ within fifteen minutes. The thermocouples were calibrated together by a platinum resistance thermometer Pt-100 (ATA-2210) in the temperature range from 15 to $100{ }^{\circ} \mathrm{C}$, the error of temperature measuring did not exceed $0.1 \mathrm{~K}$.

The pressures and temperatures in the inlet and outlet chambers of the test section were measured using the pressure probes and insulated thermocouples. The heat losses from the test section were calibrated and did not exceed $0.19 \mathrm{~W} / \mathrm{K}$. The liquid flow rate was measured by the flow controller with accuracy of $0.022 \mathrm{~g} / \mathrm{s}$.

The heat transfer coefficient was determined using internal wall temperatures $T_{w, i}$ :

$$
h_{i}=q_{w, i} /\left(T_{w, i}-T_{s a t, i}\right),
$$

where $T_{\text {sat }, i}$ is saturation temperature corresponding to the $i^{\text {th }}$ thermocouple and $q_{\mathrm{w}, i}$ is local heat flux from the inner wall to the flow. The pressure variation along the heat sink was proposed as the linear approximation of the measured input and output values. Local heat flux was determined from temperature difference $\Delta T_{w, i}$ through the partition wall as follows:

$$
q_{w, i}^{*}=\left(\frac{\delta_{s t}}{\lambda_{s t}}+\frac{\delta_{t i n}}{\lambda_{t i n}}\right)^{-1} \Delta T_{w, i}, \quad q_{w, i}=q_{w, i}^{*} \frac{A_{h s}}{A_{p r i m}+A_{f i n} \eta} .
$$

Here, $q_{w, i}^{*}$ is external local heat flux, $\lambda_{s t}$ and $\lambda_{\text {tin }}$ are thermal conductivity of stainless steel and tin, accordingly, $\delta_{\text {st }}$ and $\delta_{\text {tin }}$ are thickness of the partition wall and tin gasket, $A_{h s}$ is external area of heat sink, $A_{\text {prim }}$ is primary area of heat sink, $A_{f i n}$ is fin area, and $\eta$ is fin efficiency coefficient.

The vapor quality at the heat sink inlet was determined through heat generated in the preevaporator $Q_{\text {coil }}$ and liquid temperature at the pre-evaporator inlet $T_{0}$ was determined as:

$x_{0}=\left(Q_{\text {coil }}-Q_{\text {lost }, \text { coil }}-\dot{m} \cdot C_{p, l i q}\left(T_{\text {sat,in }}-T_{0}\right)\right) /\left(\dot{m} h_{f g}\right)$, where $\dot{m}$ is mass flow rate, $h_{f g}$ is latent heat of vaporization, and $C_{p, l i q}$ is liquid specific heat. The vapor content along the heat sink was defined as follows:

$$
x_{L_{i}}=x_{0}+\left(\int_{0}^{L_{i}} W\left\langle q_{\mathrm{w}}\right\rangle d L-Q_{\text {lost } h s} L_{i} / L_{h s}\right) /\left(\dot{m} \cdot h_{f g}\right),
$$

where $L_{h s}$ is heat sink length, $Q_{\text {lost } h s}$ is heat loss, $W$ is heat sink width, $\left\langle q_{w}\right\rangle$ is cross section averaged local heat flux supplied to heat sink, and $x_{0}$ is vapor quality at the heat sink inlet.

We verified the measurement procedure via the tests on measuring the distribution of heat transfer coefficient along the length of heat sink during the flow of subcooled refrigerant. The measured heat transfer coefficients agree well with the prediction for the laminar thermally developing flow.

\section{Pressure drop}

During adiabatic two-phase flow of R134a the friction pressure drop was determined from measurements of the wall temperature variation using data on dependence of saturation temperature on pressure.

The predominant flow pattern in microchannel heat sink is the transition flow and annular flow. Therefore, in calculation of the friction pressure drop Lockhart and Martinelly (1949) model was used. Two-phase multiplier was selected according to Chisholm (1986) model:

$$
\Phi^{2}=1+\frac{C}{X}+\frac{1}{X^{2}} .
$$

Here $X^{2}=\left(\frac{d P}{d z}\right)_{\text {liq }} /\left(\frac{d P}{d z}\right)_{\text {gas }},\left(\frac{d P}{d z}\right)_{\text {gas }}=\frac{f_{\text {gas }} G^{2} x^{2}}{2 \rho_{\text {gas }} D}$, $\left(\frac{d P}{d z}\right)_{\text {liq }}=\frac{f_{l i q} G^{2}(1-x)^{2}}{2 \rho_{l i q} D_{h}}$, friction factors for liquid flow $f_{\text {liq }}$ and gas flow $f_{\text {gas }}$ are calculated using $\operatorname{Re}_{l i q}=G(1-x) D / \mu_{\text {liq }}, \quad \operatorname{Re}_{\text {gas }}=G x D / \mu_{\text {gas }}$ accordingly.

For calculation of the friction factor for a rectangular channel during laminar flow the Shah and London (1978) equation was used: 


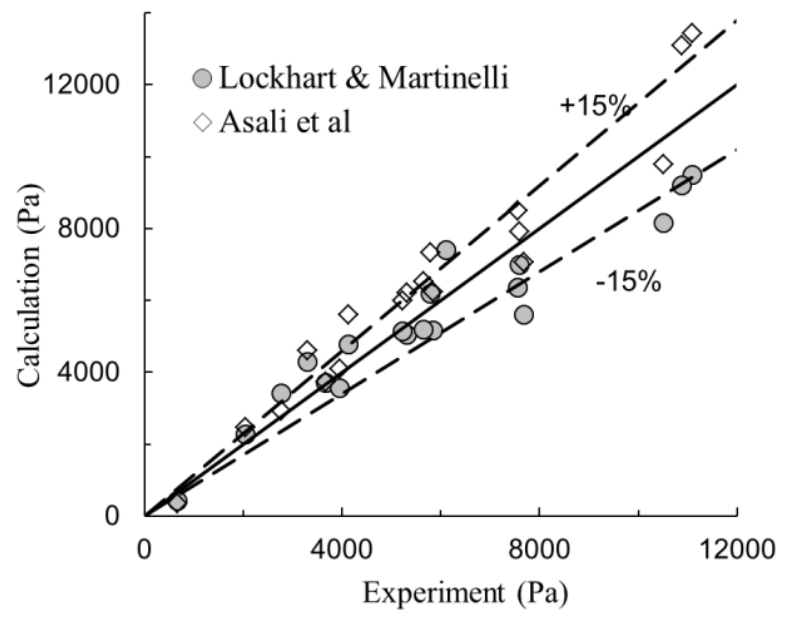

Fig. 2. Friction pressure drop during adiabatic vaporliquid flow.

$$
f \operatorname{Re}=24 \cdot\left(\begin{array}{l}
1-1.3553 \gamma+1.9467 \gamma^{2}-1.7012 \\
\gamma^{3}+0.9564 \gamma^{4}-0.2537 \gamma^{5}
\end{array}\right),
$$

where $\gamma=b / a$ is aspect ratio for a channel with depth $a$ and width $b$. For turbulent flow the Blasius equation was used in calculation of the friction factor. Criteria for selecting value of parameter $\mathrm{C}$ are given in Table 1:

Table 1. Criteria for selecting value of parameter $\mathrm{C}$.

\begin{tabular}{l|c|c}
\hline \multicolumn{1}{c|}{ Liquid } & Gas & C-value \\
\hline Laminar & Laminar & 5 \\
Laminar & Turbulent & 12 \\
Turbulent & Laminar & 10 \\
Turbulent & Turbulent & 21 \\
\hline
\end{tabular}

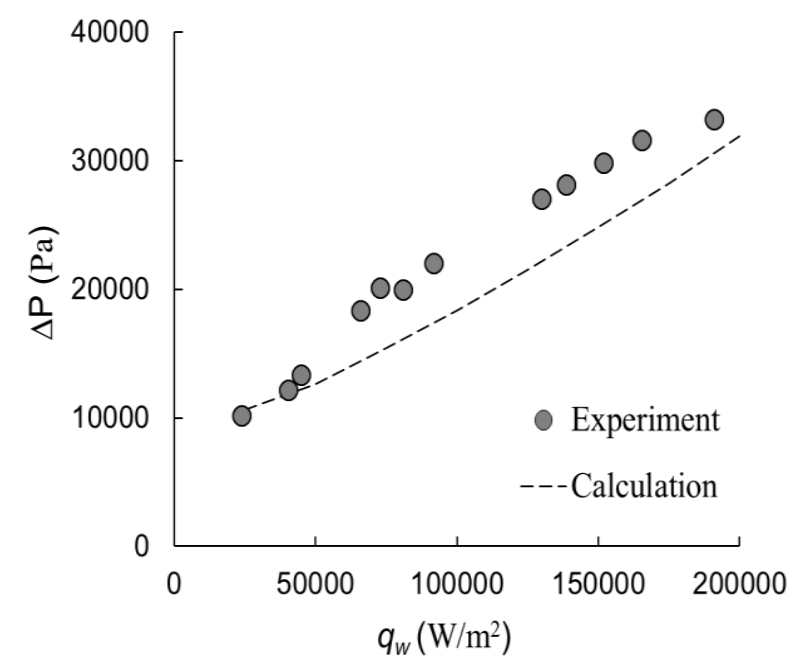

Fig. 3. Measured total pressure drop vs heat flux compared to predictions from Lockhart-Martinelly model.
Using Lockhart-Martinelly model, the friction factor was calculated as $\Delta P_{f, c h}=\Phi^{2}(d P / d z)_{l i q} L$. Figure 2 shows that the results of pressure drop calculation according to LockhartMartinelly model are in agreement with experimental data for friction pressure drop during adiabatic vapor-liquid flow, giving accuracy of the pressure drop measurements. As this figure indicates, the frictional pressure drop for mass flux of up to $600 \mathrm{~kg} / \mathrm{m}^{2} \mathrm{~s}$ does not exceed $12 \mathrm{kPa}$. Figure 2 shows also the results of pressure drop calculation according to Asali et al (1985) model. For horizontal flow the pressure drop calculations were done using the equation for co-current gas-liquid upflow with roll waves at zero gravity acceleration.

The total pressure drop during flow boiling can be represented as the sum of frictional $\left(\Delta P_{\mathrm{f}}\right)$, gravitational and momentum pressure drop $\left(\Delta P_{\mathrm{m}}\right)$ components as well as the pressure loss $\left(\Delta P_{\mathrm{c}}\right)$ and recovery $\left(\Delta P_{\mathrm{e}}\right)$ due to the inlet contraction and outlet expansion. The gravitational component can be neglected for horizontal channels. The dependence of total pressure drop on heat flux density is presented in Fig. 3. The points show experimental data corresponding to the rate of mass flux from $469 \mathrm{~kg} / \mathrm{m}^{2} \mathrm{~s}$ to $564 \mathrm{~kg} / \mathrm{m}^{2} \mathrm{~s}$, inlet quality from 0.1 to 0.06 and saturation temperature from $32 \mathrm{C}$ to $39{ }^{\circ} \mathrm{C}$. Dotted line shows the results of calculation of the total pressure drop for mass flux $550 \mathrm{~kg} / \mathrm{m}^{2} \mathrm{~s}$, inlet quality 0.07 and saturation temperature $36{ }^{\circ} \mathrm{C}$. The Lockhart Martinelli model was used for frictional pressure drop calculation. For calculations of the pressure drop across the inlet and exit of microchannel plate the model from Abdelall et al (2005) was used. For calculation of momentum pressure drop the Zivi equation was used for calculation of the void fraction. One can see that the total pressure drop for the microchannel sink is considerably higher than the friction pressure drop due to high pressure loss at the inlet and outlet of microchannel plate. It allows us to suppress the flow instability during flow boiling in microchannel heat sink. 


\section{Flow boiling heat transfer}

Measurements of local heat transfer coefficients for refrigerants R-134a flow boiling in microchannel heat sink were performed in the range of external heat fluxes from 50 to $500 \mathrm{~kW} / \mathrm{m}^{2}$; mass flux was varied within 200-600 $\mathrm{kg} / \mathrm{m}^{2} \mathrm{~s}$, and local thermodynamic vapor quality was varied from -0.02 to 1.2 . The pressure in test section was varied from 6 to 16 bars. The heat transfer coefficient was determined using the model of fin efficiency and for most experiments the fin efficiency exceeded 0.98. Flow boiling heat transfer coefficients vs. heat flux are presented in Fig. 4 for the range of mass flux from 470 to $570 \mathrm{~kg} / \mathrm{m}^{2} \mathrm{~s}$, quality variation from 0.1 to 0.3 and reduced pressure of 0.19 and 0.23 . The points show experimental data for heat fluxes on internal channel surface, obtained at the distance of $25 \mathrm{~mm}$ from the leading edge of the heat sink. For R-134a flow boiling in the microchannel heat sink, the obvious impact of heat flux on the magnitude of heat transfer coefficient was observed. It occurs, when nucleate boiling is the dominant mechanism for heat transfer.

The dotted lines in Fig. 4 show the result of calculations according to Saiz Jabardo et al. (2009) nucleate boiling equation:

$$
h_{\text {boil }}=100 q^{m}\left(p_{r}\right)^{0.45}\left(-\lg \left(p_{r}\right)\right)^{-0.80} R a^{0.2} M^{-0.5} \text {, }
$$

and Liu-Winterton forced boiling model for vapor quality of 0.2 . In Liu and Winterton (1991) model the Cooper equation was replaced by Saiz Jabardo et al. (2009) equation. Here $R a$ is surface roughness, $m=0.9-0.3 p_{r}^{0.2}$ and $p_{r}=p / p_{c r}$ is reduced pressure.

It is well known that boiling surface treatment and surface material influence nucleate boiling heat transfer significantly (Karayiannis, 2012). Saiz Jabardo et al. (2009) model was designed using experimental data for the copper boiling surface. The surface used to be treated by sand paper applied to the surface in a regular lathe machine. This model was used for prediction of R-134a nucleate boiling heat transfer on the copper surface of microchannel heat sink.
Nevertheless, one can see that calculated values are not in agreement with the experimental data and nucleate boiling model should be used with caution for prediction of flow boiling heat transfer. Continuous line in Fig. 4 shows the calculations by the model of flow boiling heat transfer, which will be discussed further.

Figure 5 shows the effect of quality on heat transfer coefficient for the range of mass flux from 250 to $350 \mathrm{~kg} / \mathrm{m}^{2} \mathrm{~s}$, heat flux from 110 to $120 \mathrm{~kW} / \mathrm{m}^{2}$ and pressure from 7 to $7.5 \mathrm{bar}$. One can see that increasing quality up to 0.6 doesn't affect the value of heat transfer coefficient. This trend was observed for positive initial quality. In case of initial subcooling the heat transfer coefficient reduces with the quality growth. It shows the

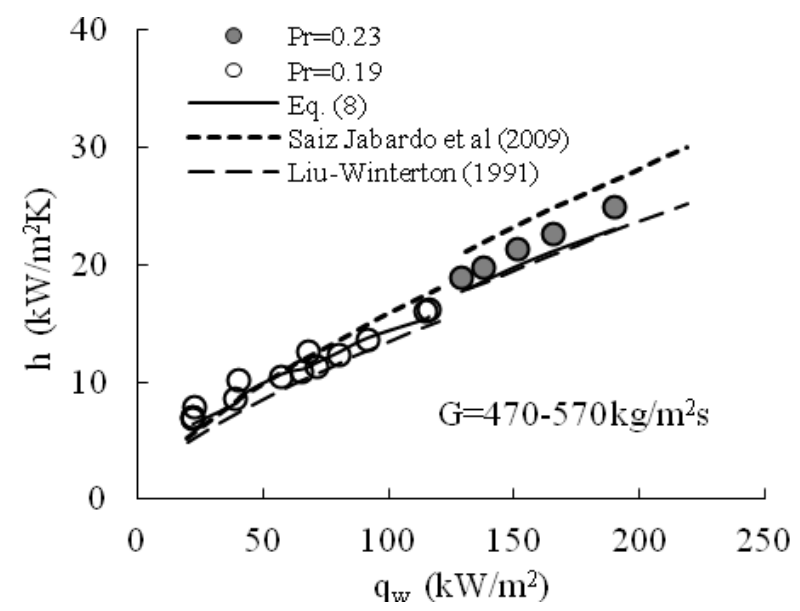

Fig. 4. Flow boiling heat transfer coefficient vs. quality. Points show experimental data, lines show the result of calculations.

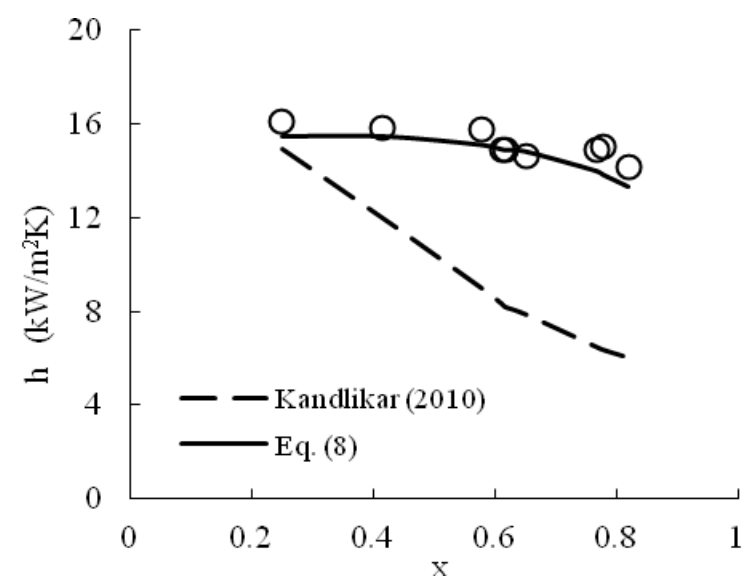

Fig. 5. Heat transfer coefficient vs. quality for average mass flux $300 \mathrm{~kg} / \mathrm{m}^{2} \mathrm{~s}$ and heat flux $115 \mathrm{~kW} / \mathrm{m}^{2}$. 
effect of flow instability on flow boiling heat transfer. To compare experimental data with predictions according to the existing models of flow boiling heat transfer, the calculations according to Kandlikar (2010) are presented as dotted line in Fig. 5. This model shows a decrease in heat transfer coefficient, when vapor quality increases. It contradicts to experimental observations.

The mechanism of flow boiling in microchannels was analysed in Kuznetsov (2010) using the available experimental data, and the Liu and Winterton (1991) model was extended to predict better the data for small size channels. In this model the heat transfer coefficient is calculated as superposition of boiling and convection terms. The important observation, performed by Kuznetsov (2010), is nucleate boiling suppression for extremely thin liquid films, when the diameter of active nucleus becomes comparable with the thermal boundary thickness. When nucleate boiling is suppressed, evaporation on a film surface becomes a significant mechanism of heat transfer. This happens, when liquid film thickness is small enough due to the capillary forces action in the elongated bubble flow or high interfacial shear stress in the annular flow. For this case the heat transfer model can be presented as follows:

$$
h^{2}=\left(h_{c o n} F\right)^{2}+\left(h_{b o i l} \Psi_{\text {sup }} S\right)^{2}+\left(h_{e v} E\right)^{2}
$$

Here $h_{\text {con }}, h_{\text {boil }}$ and $h_{\text {ev }}$ are forced convection, nucleate boiling and liquid film evaporation heat transfer coefficients, accordingly; $F$ and $S$ are the factors of forced convection enhancement and nucleate boiling suppression, which were proposed by Liu and Winterton (1991) as follows:

$$
\begin{aligned}
& F=\left(1+x \operatorname{Pr}\left(\rho_{\text {liq }} / \rho_{\text {gas }}-1\right)\right)^{0.35}, \\
& S=\left(1+0.055 F^{0.1} \operatorname{Re}_{L}^{0.16}\right)^{-1},
\end{aligned}
$$

and $\Psi_{\text {sup }}$ is boiling suppression factor introduced by Kuznetsov (2010). Evaporation factor $E$ for elongated bubble flow and transition flow equals the volume vapor fraction, $E=\left(1+\rho_{\text {gas }}(1-x) / \rho_{\text {liq }} x\right)^{-1}$, for annular flow $E=1$.

For microchannel with all-liquid flow in the laminar region, corresponding convective heat transfer coefficient $h_{\text {con }}$ should be calculated accounting to channel geometry. In our calculations we have used the correlating equation for fully developed laminar flow and thermally developing flow in a rectangular channel with constant circumferential wall temperature and uniform axial heat flux according to Shah and London (1978) equation:

$$
N u_{c o n}=8.235 \cdot\left(\begin{array}{l}
1-2.042 \gamma+3.085 \gamma^{2}-2.4765 \\
\gamma^{3}+1.0578 \gamma^{4}-0.1861 \gamma^{5}
\end{array}\right) \text {. (10. }
$$

The correct selection of nucleate boiling model $h_{\text {boil }}$ in Eq. (8) is very important for heat transfer prediction, especially for the case of dominant nucleate boiling. For microchannel's surface, made by precise milling, we propose to use Saiz Jabardo et al. (2009) equation (7).

Nucleate boiling suppression for thin liquid film was accounted by Kuznetsov (2010) using boiling suppression factor $\Psi_{\text {sup }}$ as the multiplier for nucleate boiling suppression term $S$ in Eq. (8). For the rectangular microchannel it is necessary to account the absence of nucleate boiling suppression in the meniscus area. The size of this area can be approximated as a half of the width of the channel's short side and boiling suppression factor $\Psi_{\text {sup }}$ is selected as follows:

$$
\Psi_{\text {sup }}=\left(\tanh ^{2}\left(2.5 \cdot 10^{-3} \Theta_{\text {sup }}^{2}\right)(a-b)+2 b\right)(a+b) \text {. (11 }
$$

Here $\theta_{\text {sup }}=\left(y_{\text {vis }} / d_{\text {tan }}\right)^{0.6} /\left(B o_{x}^{0.4} W e_{\text {all_liq }}^{-0.08} \operatorname{Pr}^{1 / 3}\right)$, $y_{v i s}=5 v_{l i q} / \sqrt{\tau_{w} / \rho_{l i q}}$ is thickness of the viscous sublayer in a liquid film, $B o_{x}$ is the Boiling number defined via local liquid flow rate, $d_{t a n}$ is diameter of active nucleus based on the Hsu's nucleation criterion. For calculation of shear stress $\tau_{w}$ the model of Asali et al. (1985) for roll wave regime was used.

Experimental data in Fig. 4 show that at low heat flux the heat transfer coefficient goes up as compared with the case of nucleate boiling dominant mechanism, discussed before. An increase in heat transfer coefficient could be due to an increase in contribution of film evaporation to heat transfer. In a microchannel the liquid film is very thin due to the high 


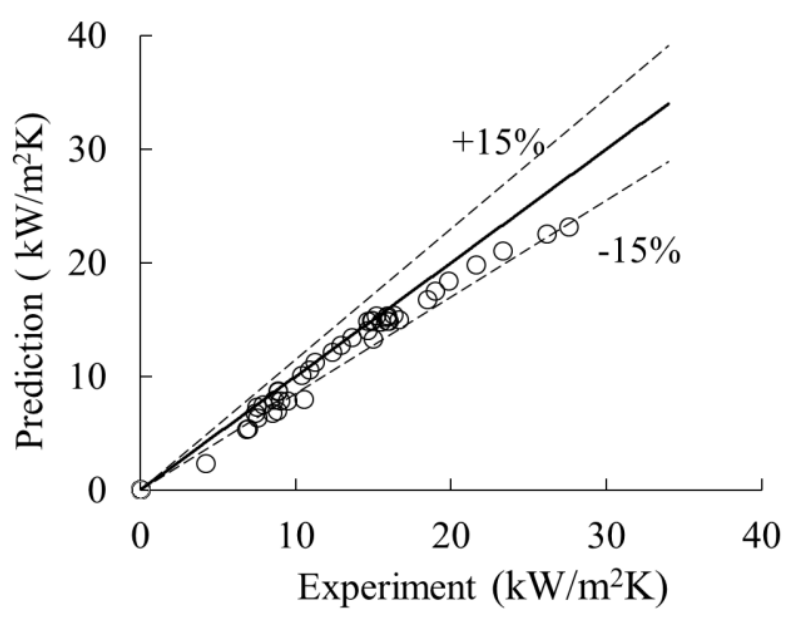

Fig. 6. Measured heat transfer coefficients vs. the predicted ones according to Eqs. (7)-(12).

surface area, and the contribution of evaporation can exceed the contribution of nucleate boiling. Thus, for the annular flow and elongated bubble flow conduction through the thin film on the channel wall could be the possible mechanism of heat transfer in the case of nucleate boiling suppression. For the elongated bubble flow, the liquid surface is controlled by capillary forces, which provide a thin liquid film inside a bubble. The heat transfer coefficient of evaporating wetting film for the elongated bubble flow can be calculated as follows:

$$
\begin{aligned}
& h_{e v}=\left(\lambda_{\text {liq }} / \delta_{e b}\right), \\
& \delta_{\mathrm{eb}} / D_{h}=0.67 C a^{2 / 3} /\left(1+3.35 C a^{2 / 3}\right)^{.}
\end{aligned}
$$

Here liquid film thickness $\delta_{e b}$ is determined by the Taylor Law (Aussillous and Quere, 2000), $C a=U_{\mathrm{s} 1} \mu_{\mathrm{liq}} / \sigma$ is the capillary number defined by bubble velocity $U_{\text {sl }}$, liquid viscosity and surface tension, $\lambda_{\text {liq }}$ is heat conductivity. To determine heat transfer coefficient of an evaporating wetting film in the annular flow, the calculation of film thickness using shear stress for wavy film (Asali et al., 1985) was used with account for limitation of heat transfer due to the film rupture. The heat transfer coefficient for ruptured film was calculated according to Kuznetsov and Safonov (2013) model and it approximately equaled 4000 for microchannel with $335 \times 930$ $\mu \mathrm{m}^{2}$ cross-section under considered condition. The results of calculation of heat transfer coefficient by Eqs. (7) - (12) are presented in
Figs. 4, 5 as the continuous black lines. One can see that proposed model suits best the experimental data for both low and high heat fluxes and mass fluxes. For data in Fig. 5 the liquid film thickness becomes small at high vapour quality and the nucleate boiling in liquid film becomes suppressed. Nevertheless, the nucleate boiling exists in meniscus area and it has dominant contribution in heat transfer coefficient.

The comparison of experimental data with predictions by Eqs. (7) - (12) for the whole studied range of heat flux and flow rate is shown in Fig. 6. One can see that calculation results are in good agreement with the experimental data for refrigerant R-134a flow boiling in microchannel heat sink. This is achieved because the proposed model is based on the contribution of nucleate boiling, forced convection and liquid film evaporation. It takes into account both nucleate boiling suppression and evaporation of thin liquid film which occur in varying degrees depending on the conditions of flow boiling.

\section{Conclusions}

Flow boiling in microchannel heat sinks is significantly influenced by the capillary forces affecting the flow pattern and heat transfer. For refrigerant R-134a flow boiling, the obvious impact of heat flux on the magnitude of heat transfer coefficient was observed. It typically occurs, when nucleate boiling is the dominant mechanism of heat transfer. Another important mechanism of flow boiling heat transfer is suppression of nucleate boiling at high vapor quality. The new model of flow boiling heat transfer, which considers nucleate boiling suppression and liquid film evaporation heat transfer, was proposed and verified experimentally in this paper. This model predicts the reduction of heat transfer coefficients at high vapor quality, if nucleate boiling suppression is predominant. If the capillary forces or interface shear stress is sufficiently high to produce extremely thin liquid film, the model predicts the heat transfer coefficient for flow boiling in microchannel heat think with refrigerant $\mathrm{R}-134 \mathrm{a}$ as the 
working fluid.

Employing smaller channel dimensions results in higher surface area and increases heat transfer performance. For considered heat sink the increase of overall heat transfer coefficient reaches $40 \%$. However, this is associated with a severe pressure drop penalty which can be carefully weighed using the well-known models for friction pressure drop and pressure drop across the inlet and exit of microchannel plate.

\section{Acknowledgments}

This work was partially supported by the research project No. 4.3 of the Division of EMEMCS of Russian Academy of Sciences.

\section{Nomenclature}

$\begin{array}{lll}a & (\mathrm{~m}) & \text { channel depth } \\ b & (\mathrm{~m}) & \text { channel width } \\ D_{\mathrm{h}} & (\mathrm{m}) & \text { hydraulic diameter } \\ F & (-) & \text { forced convection enhancement } \\ G & \left(\mathrm{~kg} / \mathrm{m}^{2} \mathrm{~s}\right) & \text { mass flux } \\ h_{f g} & (\mathrm{~J} / \mathrm{kg}) & \text { latent heat } \\ h & \left(\mathrm{~W} / \mathrm{m}^{2} \mathrm{~K}\right) & \text { heat transfer coefficient } \\ M & (\mathrm{~g} / \mathrm{mol}) & \text { molecular mass } \\ P r & (-) & \text { Prandtl number } \\ p & (\mathrm{~Pa}) & \text { pressure } \\ p_{r} & (-) & \text { reduced pressure } \\ p_{c r} & (\mathrm{~Pa}) & \text { critical pressure } \\ q_{w} & \left(\mathrm{~W} / \mathrm{m}^{2}\right) & \text { heat flux density } \\ R e & (-) & \text { Reynolds number } \\ R_{a} & (\mu \mathrm{m}) & \text { roughness } \\ W e & (-) & \text { Weber number } \\ \Psi_{\text {sup }} & (-) & \text { boiling suppression factor } \\ \tau & (\mathrm{Pa}) & \text { shear stress } \\ v & \left(\mathrm{~m}^{2} / \mathrm{s}\right) & \text { kinematical viscosity } \\ \delta & (\mathrm{m}) & \text { film thickness }\end{array}$

\section{References}

Abdelall, F.F., Hahm, G., Ghiaasiaan, S.M., AbdelKhalik, S.I., Jeter, S.S., Yoda, M., Sadowski, D.L., 2005. Pressure drop caused by abrupt flow area changes in small channels. Exp. Thermal Fluid Sci. 29, 425-434.

Asali, J.C., Hanratty, T.J., Andreussi, P., 1985. Interfacial Drag and Film Height for Vertical Annular Flow. AlChE J. 31, 886-902.

Aussillous, P., Quere, D., 2000. Quick Deposition of a Fluid on the Wall of a Tube. Phys. of Fluids 12, 2367-2371.

Bertsch, S.S., Groll, E.A. and Garimella, S.V., 2009. Effects of heat flux, mass flux, vapor quality, and saturation temperature on flow boiling heat transfer in microchannels. Int. J. Multiphase Flow $35,142-154$.

Chisholm, D., 1983. Two-Phase Flow in Pipelines and Heat Exchangers. England: Pitman Press, 175-192.

Kandlikar, S.G., Balasubramanian, P., 2004. An Extension of the Flow Boiling Correlation to Transition, Laminar, and Deep Laminar Flows in Mini-Channels and Micro-Channels. Heat Transfer Eng. 25, 86- 93.

Kandlikar, S.G., 2010. Similarities and Differences Between Flow Boiling in Microchannels and Pool Boiling. Heat Transfer Eng. 31, 159 - 167.

Karayiannis, T.G., Mahmoud, M.M., Kenning, D.B.R., 2012. A study of discrepancies in flow boiling results in small to microdiameter metallic tubes. Exp. Therm. Fluid Sci. 36, 126-142.

Kuznetsov, V.V., Shamirzaev, A.S., 2007. Boiling Heat Transfer for Freon R21 in Rectangular Minichannel. Heat Transfer Eng. 28, 738-745.

Kuznetsov, V.V., 2010. Heat and mass transfer with phase change and chemical reactions in microscale. Proc. of the Int. Heat Transfer Conf. IHTC14, IHTC14-22570.

Kuznetsov, V.V., Safonov, S.A., 2013. Fluid flow and heat transfer with phase change in minichannels and microchannels. Heat pipes and solid sorption transformations fundamentals and practical applications, ed. L.L. Vasiliev, S. Kakac. CRC Press, Boca Raton, 465-496.

Lee, J., Mudawar, I., 2005. Two phase flow in high-heat flux micro-channel heat sink for refrigeration cooling applications: Part II - heat transfer characteristics. Int. J. Heat Mass Transfer 48, 941955.

Liu, Z., Winterton, R.H.S., 1991. A General Correlation for Saturated and Subcooled Flow Boiling in Tubes and Annuli, Based on a Nucleate Pool Boiling Equation. Int. J. Heat Mass Transfer 34, 2759-2766.

Lockhart, R.W., Martinelli, R.C., 1949. Proposed correlation of data for isothermal two-phase, twocomponent flow in pipes. Chemical Eng. Prog. 45, 39-48.

Saiz Jabardo, J. M., Ribatski, G., Stelute, E., 2009. Roughness and surface material effects on nucleate boiling heat transfer from cylindrical surfaces to refrigerants R-134a and R-123. Exp. Thermal Fluid Sci. 33, 579-590.

Shah, R.K., London, A.L., 1978. Laminar Flow Forced Convection in Ducts. Supplement 1 to Advances in Heat Transfer, New York: Academic Press.

Thome, J.R., Dupont, V., Jacobi, A.M., 2004. Heat Transfer Model for Evaporation in Microchannels. Part I: Presentation of the Model. Int. J. Heat Mass Transfer 47, 3375-3385.

Thome, J.R., 2006. State-of-the-Art Overview of Boiling and Two-Phase Flows in Microchannels. Heat Transfer Eng. 27, 4-19. 